\title{
Visual recognition thresholds and dimensions of word meaning ${ }^{1}$
}

\author{
ALLAN PAIVIO ${ }^{2}$ AND BRIAN J. O'NEILL \\ UNIVERSITY OF WESTERN ONTARIO
}

\begin{abstract}
Tachistoscopic recognition thresholds were obtained for nouns with high or low values on one dimension of meaning while two others were controlled. Frequency, imagery concreteness (I), and meaningfulness $(m)$, were varied in different lists in one experiment, frequency and $m$ in a second, and $m$ alone in a third. Ratings of familiarity were also obtained to supplement frequency as a measure of familiarity. The results showed that ease of visual recognition was most strongly related to frequency and familiarity. Imagery was unrelated to thresholds when familiarity and $m$ were controlled. Meaningfulness showed a small but consistent positive relation to ease of recognition even with the other variables held constant. Except for the puzzling effect of $m$, the results are consistent with the view that perceptual recognition is primarily dependent upon the familiarity of the target stimulus and not upon associative processes evoked by it.
\end{abstract}

Perceptual recognition thresholds for verbal stimuli may be affected by a number of stimulus attributes related to meaning. Familiarity, meaningfulness, and concreteness of words are among the dimensions that have been investigated, although the findings have been reliable only in the case of familiarity. Whether familiarity is defined experimentally or in terms of word frequency counts, familiar words have consistently been found easier to recognize than unfamiliar words (for summaries, see Dember, 1960, and Neisser, 1967). Meaningfulness as defined by production $m$ (Noble, 1952) has been found to be unrelated to tachistoscopic thresholds in some studies (Taylor, 1958; Winnick \& Kressel, 1965) whereas others have found $m$ to be effective in visual recognition (Kristofferson, 1957) and in signal-to-noise auditory perception (Spreen, Borkowski, \& Benton, 1967). Contrasting evidence in regard to word concreteness likewise indicates facilitative effects of concreteness on visual duration thresholds (Riegel \& Riegel, 1961) and on auditory recognition (Spreen et al, 1967) on the one hand, and no effect on visual thresholds on the other (Taylor, 1958; Winnick \& Kressel, 1965).

The position adopted in the present study was that familiarity alone should be related to recognition thresholds. This follows from a theoretical analysis of meaning in terms of representational, referential, and associative levels. The first of these refers to the availability of some form of memory representation corresponding to the physical stimulus. Such a representation presumably is a function of frequency of experience with a stimulus pattern, which determines the ease with which the pattern will arouse the stored symbolic representation, thereby affecting the probability of a correct recognition response. The second level, referential meaning, is most obviously interpreted in terms of the availability of a verbal label for a nonverbal stimulus. Such a definition would be relevant to studies concerned with the effect of verbal codability on perceptual recognition of nonverbal stimuli (e.g., Epstein, 1967), but it is not directly relevant in the present study. What is relevant here is the reverse relation, that is, the availability of a nonverbal representation, such as an image, as an associative reaction to the verbal label. Referential meaning in the latter sense can be defined in terms of the latency of image arousal or concreteness of the words (see Paivio, 1969). Associative meaning is a further level that can be defined partly in terms of the availability of other words as associative reactions to the stimulus. Production $m$ obviously represents one possible operational definition of such meaning.

According to the present view, only representational meaning should be related to recognition thresholds because only the availability of a symbolic representation that corresponds most directly to the stimulus itself should be relevant for its recognition. Referential and associative meaning refer to higher-order processes aroused by the stimulus after it has been identified, and there seems to be no good theoretical basis for assuming that such processes can work backward to affect recognition of the stimulus on which their arousal depends. To argue otherwise would require one to postulate a perceptual mechanism that is sensitive to meaning independent of word recognition. Such a mechanism is regarded as unnecessary and implausible in the present context as it has been found by others (e.g., Neisser, 1967, pp. 126-134; Zuckerman \& Rock, 1957) in relation to perceptual defense, "semantic subception," and issues related to connotative meaning of words and experiential variables generally. On the other hand, referential and associative meaning should be highly relevant in memory tasks where the associative processes have time to operate, and this expectation has been strongly supported in the case of imaginal referential meaning in particular (Paivio, 1969).

The consistent facilitating effect of word frequency and the inconsistent effects of concreteness and $m$ on perceptual recognition are to some extent in accord with the above analysis. However, as already noted, there are exceptions in the case of the latter two variables. The discrepancies in the findings for concreteness may be attributable partly to differences in the operational definitions of the variable. In the Riegel and Riegel study, for example, $32 \%$ of the stimulus items used were from word classes other than nouns. All but one of these items were in the highest $50 \%$ in terms of threshold values, suggesting that word class per se rather than concreteness may have been the effective variable in their study. Perhaps similar factors have confounded effects of $\mathrm{m}$. The present study sought to resolve the ambiguities by investigating the effects of familiarity, $m$, and imagery concreteness in a single experimental design, and using recent norms in order to exercise better control over the covarying word attributes. It was expected that familiarity alone would be related to tachistoscopic recognition.

\section{Experiment 1}

\section{Method}

Materials and design. Two samples of stimulus words, each comprising 16 nouns, were selected from available norms (Paivio, Yuille, \& Madigan, 1968). In one word sample, familiarity and verbal associative meaningfulness were orthogonally varied: These attributes are operationally defined in terms of Thorndike and Lorge (1944) frequency counts and production $m$ (Noble, 1952), respectively. Half of the words were of high-frequency value $(\bar{x}=62.5$, with words of $A$ and $A A$ frequency assigned values of 50 and 100) and the remainder were relatively low-frequency items $(\bar{x}=3.12)$. Half of the words of each frequency level were high $\mathrm{m}$ $(\bar{x}=6.35)$ and half were low $m(\bar{x}=4.00)$. Imagery (I), defined by mean ratings of the 
ease with which a noun elicits an image, was held relatively constant (mean $I=3.37 ; \mathrm{SD}=0.47$ ) over the four treatment combinations. In the second group of 16 nouns, high $(\bar{x}=87.5)$ and low frequency $(\bar{x}=3.13)$ and high $(\bar{x} \approx 6.33)$ and low 1 $(\bar{x}=2.81)$ were orthogonally combined to produce an additional four treatments, while $m$ was held relatively constant (mean $m=5.70 ; S D=0.43$ ). Thus, a total of eight treatment combinations were represented in the two lists in an incomplete factorial design. Mean word length $(\overline{\mathrm{x}}=7.25)$ was the same for each treatment group of words. Noun concreteness and I were covaried; reference to one, therefore, also implies the other.

Subjects and procedure. Ten undergraduate students from introductory classes at the University of Western Ontario acted as Ss. Each $S$ was tested individually and served in all experimental conditions. Each word, typed in elite capitals on a card, was presented using a Gerbrands two-channel Harvard tachistoscope. Order of presentation of the words was randomized for each $S$. The $S$ was instructed to fixate the center of the preexposure field and to try to identify each word as it flashed between two parallel lines penciled onto the preexposure surface. Upon a verbal signal from the $E, S$ initiated the stimulus exposure by depressing a button. The ascending method of limits was used starting at $10 \mathrm{msec}$ and increasing in 5-msec intervals until one correct identification was made. A minimum interval of $5 \mathrm{sec}$ occurred between presentations. The $S$ was encouraged to attempt an identification even when not completely certain.

\section{Results and Discussion}

Two separate 2 by 2 analyses of variance for repeated measures were carried out on the thresholds. Significant main effects were obtained in one analysis for frequency, $F(1,9)=12.16, p<.01$, and for $m, F(1,9)=13.82, p<.01$, and in the other analysis for frequency $\mathrm{F}(1,9)=24.51, \mathrm{p}<.01$, and $I$ $F(1,9)=10.76, p<.01$. In neither case did the two variables interact significantly $F(1,9) \leqslant 3.49$. The mean threshold values presented in Table 1 indicate that the frequency effect was as predicted: Thresholds were lower for high-frequency than for low-frequency words. However, $m$ was also related positively to ease of recognition whereas the effect of 1 was in the opposite direction, i.e., thresholds were lower for abstract than for concrete words. Thus the results for $m$ and $I$ did not accord with what was predicted for these variables.

It seemed possible that Thorndike-Lorge

Table 1

Mean Tachistoscope Recognition Thresholds in Milliseconds as a Function of Word Frequency (F), Imagery (I), and Meaningfulness ( $m$ )

\begin{tabular}{|c|c|c|c|c|}
\hline & \multicolumn{2}{|c|}{ High $\mathbf{F}$} & \multicolumn{2}{|c|}{ Low I: } \\
\hline & Mean & SD & Mean & $\mathrm{SD}$ \\
\hline Experiment & & & & \\
\hline $\begin{array}{l}\text { High I } \\
\text { Low I } \\
\text { High m } \\
\text { Low m }\end{array}$ & $\begin{array}{l}17.13 \\
16.88 \\
16.25 \\
20.50\end{array}$ & $\begin{array}{l}6.96 \\
6.97 \\
5.65 \\
9.03\end{array}$ & $\begin{array}{l}25.50 \\
20.50 \\
20.63 \\
28.63\end{array}$ & $\begin{array}{r}6.81 \\
5.95 \\
7.65 \\
11.37\end{array}$ \\
\hline $\begin{array}{c}\text { Experiment } \\
\text { High } \mathrm{m} \\
\text { Low } \mathrm{m} \\
\end{array}$ & $\begin{array}{l}15.09 \\
14.65\end{array}$ & $\begin{array}{l}5.69 \\
4.57 \\
\end{array}$ & $\begin{array}{l}16.20 \\
30.75\end{array}$ & $\begin{array}{r}5.19 \\
13.99\end{array}$ \\
\hline
\end{tabular}

frequency counts inadequately defined familiarity and that the obtained $m$ and $I$ effects were attributable to uncontrolled familiarity. Accordingly, additional data were collected from the experimental Ss. Each stimulus word was rated for printed familiarity using a seven-point rating scale. Mean familiarity scores were obtained for each word and correlations computed between the mean threshold, familiarity, 1 , and $m$ values for the words.

For the I-varied list, rated familiarity correlated -.54 with $\mathrm{I}(\mathrm{df}=14, \mathrm{p}<.05)$ and -.63 with thresholds (df $=14$, $\mathrm{p}<.01$ ). When rated familiarity was partialed out, a correlation of .28 between I values and thresholds was reduced to zero. With I partialed out, however, the correlation between familiarty and thresholds remained a significant -.59 ( $\mathrm{df}=13, \mathrm{p}<.05)$. For the $\mathrm{m}$-varied list mean familiarity ratings correlated .42 with $\mathrm{m}$ (df $=14, \mathrm{p}>.1)$ and -.55 with thresholds $(\mathrm{df}=14, \mathrm{p}<.05)$. With familiarity partialed out, a correlation of -.45 between $m$ and thresholds $(\mathrm{df}=14$, $\mathrm{p}<.05)$ was reduced to $-.29(\mathrm{df}=13$, p>.1). The partial correlation between familiarity and thresholds, with $m$ held constant, remained significant, $r=-.45$ $(d f=13, p<.05)$. The results of the correlation analysis support the conclusion that familiarity has a strong positive influence on word recognition and that $I$ has no significant effect. However, the contribution of $m$ to ease of recognition was more equivocal, and a second experiment was undertaken to test further the relative influence of familiarity and $\mathrm{m}$.

\section{EXPERIMENT 2}

\section{Method}

A total of 32 stimulus nouns were selected from the norms such that frequency and $m$ were orthogonally varied as in Experiment 1. The words were high and low in frequency (means $=66.5$ and 4.13 , respectively, with $\mathrm{AA}$ and $\mathrm{A}$ words assigned values of 100 and 50 ), and high and low in $m$ (means $=6.37$ and 4.20). Mean I values were constant across treatment conditions (mean $I=3.79$; $\mathrm{sd}=0.66$ ). Mean word length was 7.00 for each of the four sets of words. Fifteen Ss from the same population as before participated, and the procedure was identical to that of Experiment 1.

\section{Results and Discussion}

Mean threshold values are presented in Table 1 . The results of a 2 by 2 analysis of variance for repeated measures again revealed significant main effects of frequency $F(1,14)=20.56, p<.001$ and $\mathrm{m}, \mathrm{F}(1,14)=21.95, \mathrm{p}<.001$. In addition, the Frequency by $m$ interaction was highly significant, $F(1,14=19.79, p<.001$. Since Since these results again failed to indicate an exclusive effect of familiarity, ratings were obtained from the experimental Ss, as before, on the printed familiarity of the words. Correlations were computed between mean familiarity, mean threshold, $I$, and $m$ values for the stimulus items. Familiarity correlated .61 with $\mathrm{m}(\mathrm{df}=30$, $p<.01)$ and -.71 with thresholds ( $d f=30, p<.01)$. With familiarity controlled, the correlation of -.62 between $m$ and thresholds was reduced to -.34 , which was significant $(\mathrm{df}=29$, $p<.05)$. The correlation between familiarity and threshold values, with $m$ partialed out, was a highly significant -.53 ( $d f=29, p<.01$ ). The results therefore confirmed the findings of the first experiment: $m$ appears to exert a significant influence on the tachistoscopic recognition of words, although the effect of familiarty is clearly greater.

A final experiment was performed to test the reliability of the $m$ effect once more.

\section{Method}

\section{EXPERIMENT 3}

Materials. In order to exercise greater experimental control over the independent variables, mean familiarity ratings were obtained preexperimentaly for all of the nouns in the Paivio et al (1968) norms. Essentially the same rating procedure as before was employed with mean familiarity values computed for each word on the basis of ratings made by 14 Ss. A total of 
92 summer school students at the University of Western Ontario served as Ss in this part of the experiment, with different subgroups rating different sets of words.

Twenty nouns, 10 high $\mathrm{m}(\overline{\mathrm{x}}=6.51$; $\mathrm{SD}=0.42)$ and 10 low $\mathrm{m}(\mathrm{m}=4.87$; $\mathrm{SD}=0.22$ ) were selected from the norms. The other attributes were controlled such that their means and (in parentheses) standard deviations for high-m and low-m nouns, respectively, were $4.43(.79)$ and 4.02 (.56) for rated $I ; 5.41(.52)$ and 5.40 (.53) for rated familiarity; and $25.60(7.0)$ and $25.30 \quad(7.1)$ for Thorndike-Lorge frequency. The mean word length for each $\mathrm{m}$ level was 6.80 letters.

Subjects and procedure. The Ss were 15 summer school students none of whom had participated in the rating of the words. Mean perceptual thresholds for both levels of $m$ were determined for each $S$ under the same experimental conditions as before.

\section{Results}

Mean thresholds, measured in msec, were $17.77(\mathrm{SD}=5.21)$ for high $\mathrm{m}$ nouns and $20.77(\mathrm{SD}=6.08)$ for low $\mathrm{m}$ nouns. The difference between means was significant, $\mathrm{t}(14)=2.95, \mathrm{p}<.02$, thus confirming once more that $\mathrm{m}$ influences tachistoscrspic recognition.

\section{DISCUSSION}

The strong relations obtained for familiarity in Experiments 1 and 2 support the hypothesis that representational meaning, as defined by word frequency or familiarity, is the primary determinant of visual thresholds in word recognition. The results of Experiment 1 also indicate that word imagery has no influence on visual recognition. This finding agrees with Winnick and Kressel (1965) but not with Riegel and Riegel (1961). Since the preponderance of evidence goes against Riegel and Riegel, it seems likely that their finding reflects uncontrolled variation on some word attribute other than concreteness. By contrast, other investigations have shown noun imagery to be highly potent in various learning and memory tasks (see Paivio, 1969). Nouns that are rated as concrete and high in imagery are assumed to elicit referential images that can be used as an alternative memory code or associative mediator. The absence of any effect of $I$ in Experiment 1 is consistent with the conclusion that such referential images do not work backward to affect perceptual recognition.

Comparisons involving frequency and $m$ in the first two experiments clearly show that frequency is the more potent variable, but all three experiments also attribute some residual effect to $m$. This effect of $m$ is not in accord with what was expected. Like imagery, verbal associative meaningfulness was considered to be functionally relevant only in learning or memory tasks that implicate verbal associative processes. It has been suggested that perceptual clarity may be increased by feedback to the perceptual system from "some sort of cognitive organisational framework (structure), relevant to the stimuli [Hershenson \& Haber, 1965]." The occurrence of cognitive feedback appears to be dependent on the degree of meaning inherent to the stimulus. Insofar as associative meaningfulness can be regarded as one dimension of meaning, the theory proposed by Hershenson and Haber may serve to explain the present findings. However, no mechanism has been posited to account for the activation of a cognitive structure prior to the recognition of a word in the absence of any priming stimulus.

Since no adequate theoretical explanation has as yet been offered to account for the positive influence of $m$ on visual recognition, the possibility must again be considered that some covariate of $\mathrm{m}$, rather than the number of associations per se, is responsible for the effect. Some structural features, such as the predictability of the word from the first three letters (estimated from word-completion data obtained from an independent group of $\mathrm{Ss}$ ), were considered in the present study, but these failed to account for the effect of $m$. The relation poses an interesting puzzle, particularly since its reliability contrasts with the inconsistent effects of noun $m$ (varying from slightly positive, to zero, to slightly negative) in various verbal-learning experiments (see Paivio, 1969). In this respect, $m$ is somewhat like word frequency, which also has inconsistent effects in learning and memory. The most notable anomaly is that recognition memory is worse for frequent than for rare words (e.g., Gorman, 1961; Shepard, 1967), contrasting directly with the strong positive effect of frequency in perceptual recognition. A common interpretation is possible: Both frequency and $m$ may have their inconsistent and occasionally negative effects in learning and memory tasks because of interfering verbal associations aroused by words with high values on these attributes (cf. Postman, 1962). To be consistent with the present theoretical approach, the positive effect of both variables on perceptual recognition would be attributed solely to the availability of representational responses to the stimulus words. The manner in which number of associations per se might operate to affect the availability of stimulus words varying in $\mathrm{m}$ remains obscure.

\section{REFERENCES}

DEMBER, W. N. Psychology of perception. New York: Holt, 1960.

EPSTEIN, W. Varieties of perceptual learning. New York: McGraw-Hill, 1967.

GORMAN, A. M. Recognition memory for nouns as a function of abstractness and frequency. Journal of Experimental Psychology, 1961, 61, 23-29.

HERSHENSON, M., \& HABER, R. N. The role of meaning on the perception of briefly presented words. Canadian Journal of Psychology, $1965,19,42-46$.

KRISTOFFERSON, A. B. Word recognition, meaningfulness, and familiarity. Perceptual \& Motor Skills, 1957, 7, 219-220.

NEISSER, U. Cognitive psychology. New York: Appleton-Century-Crofts, 1967.

NOBLE, C. E. An analysis of meaning. Psychological Review, 1952, 59, 421-430.

PAIVIO, A. Mental imagery in associative learning and memory. Psychological Review, 1969, 76, 241-263.

PAIVIO, A., YUILLE, J. C., \& MADIGAN, S. Concreteness, imagery, and meaningfulness values for 925 nouns. Journal of Experimental Psychology monograph Supplement, 1968, 76, No. 1., Part 2, 1-25.

POSTMAN, L. The effects of language habits on the acquisition and retention of verbal associations. Journal of Experimental Psychology, 1962, 64, 7-19.

RIEGEL, K. F., \& RIEGEL, R. M. Prediction of word-recognition thresholds on the basis of stimulus-parameters. Language \& Speech, $1961,4,157-170$.

SHEPARD, R. N. Recognition memory for words, sentences, and pictures. Journal of Verbal Leaming \& Verbal Behavior, 1967, 6, 156-163.

SPREEN, O., BORKOWSKI, J. G., \& BENTON A. L. Auditory recognition in relation to meaningfulness, abstractness, and phonetic structure of words. Journal of Verbal Learning \& Verbak Behavior, 1967, 6, 101-104.

TAYLOR, J. A. Meaning, frequency, and visual duration threshold. Journal of Experimental Psychology, 1958, 55, 329-34.

THORNDIKE, E. L., \& LORGE, I. The teacher's word book of 30,000 words. New York: Bureau of Publications, Teachers College, 1944.

WINNICK, W. A., \& KRESSEI, K. Tachistoscopic recognition thresholds, paired-associate learning, and immediate recall as a function of abstractness-concreteness and word frequency. Joumal of Experimental Psychology, 1965, 70, 163-168.

ZUCKERMAN, C. B., \& ROCK, I. A reappraisal of the roles of past experience and innate organizing processes in visual perception. Psychological Bulletin, 1957, 54, 269-296.

\section{NOTES}

1. This research was supported by grants to the first author from the National Research Council of Canada (APA-87) and from the University of Western Ontario Research Fund.

2. Address: Department of Psychology, University of Western Ontario, London, Ontario, Canada.

(Accepted for publication December 31, 1969.) 